\title{
Predictors for In-hospital Mortality in Pediatric Patients with Acute Myocarditis - a Retrospective Study
}

\author{
Daniela Toma ${ }^{1,2}$, Liliana Gozar ${ }^{1,2}$, Carmen Corina Șuteu², Amalia Făgărășan ${ }^{1,2}$, \\ Rodica Togănel ${ }^{1,2}$ \\ 1 "George Emil Palade" University of Medicine, Pharmacy, Science and Technology, Târgu Mureș, Romania \\ 2 Emergency Institute of Cardiovascular Diseases and Transplantation, Târgu Mureș, Romania
}

\section{ABSTRACT}

Background: Acute myocarditis, a primary inflammatory cardiac disease commonly caused by viral infection, is an important cause of morbidity and mortality in children. Data obtained from forensic studies found an incidence of $15-33 \%$ for acute myocarditis in sudden deaths in the pediatric age group. Currently, there is a lack of data regarding the incidence and factors associated with short-term outcomes in pediatric patients admitted for acute myocarditis. The aim of the study was to identify predictors for in-hospital mortality in a pediatric population admitted with acute myocarditis. Material and methods: We conducted a retrospective observational cohort study that included 21 patients admitted for acute myocarditis. Clinical, laboratory, ECG, and imaging data acquired via $2 \mathrm{D}$ transthoracic echocardiography and cardiac magnetic resonance imaging were collected from the medical charts of each included patient. The primary end-point of the study was all-cause mortality occurring during hospitalization (period ranging from 10 to 14 days). The study population was divided into 2 groups according to the occurrence of the primary end-point. Results: The mean age of the study population was $99.62 \pm 77.25$ months, and $61.90 \%$ $(n=13)$ of the patients were males. The in-hospital mortality rate was $23.9 \%(n=5)$. Patients in the deceased group were significantly younger than the survivors ( $55.60 \pm 56.18$ months vs. $113.4 \pm$ 78.50 months, $\mathrm{p}=0.039$ ). Patients that had deceased presented a significantly higher level of LDH $(365 \pm 21.38 \mathrm{U} / \mathrm{L}$ vs. $234.4 \pm 63.30 \mathrm{U} / \mathrm{L}, \mathrm{p}=0.0002)$ and a significantly higher rate of ventricular extrasystolic dysrhythmias (60\% vs. 6.25\%, p = 0.02, OR: 22.5, 95\% CI: 1.5-335) compared to survivors. The $2 \mathrm{D}$ echocardiography showed that patients that had deceased presented more frequently an impaired left ventricular ejection fraction $(<30 \%)(p=0.001)$ and a significantly higher rate of severe mitral regurgitation $(\mathrm{p}=0.001)$ compared to survivors. Conclusions: The most powerful predictors for in-hospital mortality in pediatric patients admitted for acute myocarditis were the presence of ventricular extrasystolic dysrhythmias on the 24h Holter ECG monitoring, impaired left ventricular systolic function ( $\mathrm{LVEF}<30 \%$ ), the presence of severe mitral regurgitation, and confirmed infection with Mycoplasma pneumoniae.

Keywords: acute myocarditis, pediatric population, in-hospital mortality

\section{ARTICLE HISTORY}

Received: November 17, 2019 Accepted: December 16, 2019 


\section{INTRODUCTION}

Acute myocarditis is a primary inflammatory cardiac disease with a favorable prognosis, the full recovery rate being around $80 \%$. The most frequent etiology of acute myocarditis in children is a viral infection (adenoviruses, enteroviruses). The real prevalence of myocarditis in the pediatric population is still unknown. ${ }^{1-3}$ And even though the incidence of pediatric myocarditis is also unknown, current published data confirm the high mortality rates amongst infants and young children, ranging from $25 \%$ to $75 \%$. Data obtained from forensic studies found an incidence of $15-33 \%$ for acute myocarditis in sudden deaths in the pediatric age group..$^{4-6}$ Despite its rarity, the illness is an important cause of morbidity and mortality in children. ${ }^{7,8}$ Myocarditis can lead to heart failure, dilated cardiomyopathy, or death. The disease frequently has an insidious onset, and often patients present a recent history of a viral infection.

The initial diagnosis is based on the clinical presentation, which may vary from a lack of symptoms to signs of cardiogenic shock ${ }^{1,9-12}$ Cardiovascular signs are minimal, but certain signs of heart failure, tachycardia, hypotension, syncope (full atrioventricular block or other tachyarrhythmia), chest pain, or even cardiogenic shock can also be found. ${ }^{2,8,11-15}$ Since there are some cases when the diagnosis can be omitted, a full paraclinical examination is recommended in any clinical suspicion for acute myocarditis, which should include viral serology, cardiac enzymes (lactate dehydrogenase [LDH], creatine kinase [CK], creatine kinase myocardial band [CK-MB], T troponin, brain natriuretic peptide [BNP]), and transaminases, along with an electrocardiogram (ECG), which may reveal nonspecific modifications of the ST segment and the $\mathrm{T}$ wave, micro voltage, certain arrhythmias. Furthermore, the cardiac structures and function should be assessed by using noninvasive imaging techniques such as echocardiography or chest X-ray (for assessing cardiomegaly and pulmonary vascular load). ${ }^{11,15-21}$ In the present, noninvasive techniques such as cardiac magnetic resonance (CMR) with contrast enhancement have been very useful in supporting the diagnosis of myocarditis. A definitive diagnosis is achieved by histological criteria, immunological and immunohistochemistry findings in myocardial tissue samples obtained by endomyocardial biopsy (EMB).

The management and diagnosis of patients with acute myocarditis remains a challenge..$^{4,5,9-12,23}$ Currently, there is a lack of data regarding the incidence and factors associated with short-term outcomes in pediatric patients admitted for acute myocarditis.
The aim of this study was to identify clinical and paraclinical (laboratory, ECG, imaging) predictors for in-hospital mortality in a pediatric population admitted for acute myocarditis.

\section{MATERIAL AND METHODS}

The study included 21 patients admitted with acute myocarditis in the Pediatric Cardiology Clinic of the Transplant and Cardiovascular Disease Institute from Târgu Mureș, between January 2013 and June 2018. The study was performed according to the principles stated in the Declaration of Helsinki and was approved by the local Ethics Committee of the institution in which the study was conducted.

The retrospective observational cohort study was based on analyzing the observational charts of the 21 patients, with ages ranging from 1 month to 18 years, both female and male. The diagnosis was confirmed based on: (1) laboratory findings: full blood count, inflammatory biomarkers (serum levels of C-reactive protein), biomarkers of cardiac injury: aspartate transaminase (ASAT), alanine transaminase (ALAT), LDH, CK and isoenzyme CK-MB, as well as T troponin; (2) ECG findings suggestive of cardiac injury; (3) arrhythmia on 24h Holter ECG; (4) echocardiography revealing abnormal left ventricular systolic function or dilatation, segmental wall motion abnormalities, mitral regurgitation, abnormal index of left ventricle contractility $\mathrm{dP} / \mathrm{dt}$; and (5) typical hyperenhancement on late gadolinium-enhanced cardiac magnetic resonance imaging (MRI). Myocardial biopsy was performed in only four cases, since EMB was not fully available in our institution during the study period.

The primary end-point of the study was all-cause mortality occurring during hospitalization (which ranged from 10 to 14 days). The study population was divided into two groups according to the occurrence of the primary end-point.

\section{STATISTICAL ANALYSIS}

The data obtained was entered into a Microsoft Office Excel database and subsequently processed using the GraphPad Prism 7 software (GraphPad Software San Diego, CA, USA). Quantitative data were tested for normality of distribution using the D'Agostino Pearson Omnibus test and were subsequently compared with Student's $t$ test or the Mann-Whitney test when appropriate. Nominal data were analyzed using the Chi square test or its alternates when appropriate and were expressed as numbers and percentages. Multivariate analysis was per- 
TABLE 1. Baseline clinical, laboratory, ECG and imaging characteristics of the study population

\begin{tabular}{|c|c|}
\hline \multicolumn{2}{|l|}{ Characteristics } \\
\hline Age, months & $99.62 \pm 77.25$ \\
\hline Gender, male & $13(61.90 \%)$ \\
\hline \multicolumn{2}{|l|}{ Clinical presentation } \\
\hline Peripheral edema & $1(4.76 \%)$ \\
\hline $\begin{array}{l}\text { Digestive symptoms (nausea, vomiting, de- } \\
\text { creased appetite) }\end{array}$ & $7(33.33 \%)$ \\
\hline Respiratory symptoms (dyspnea, tachypnea) & $11(52.38 \%)$ \\
\hline Sweating & $6(28.57 \%)$ \\
\hline Hepatomegaly & $8(38.09 \%)$ \\
\hline Chest pain & $10(47.61 \%)$ \\
\hline Sensory deficit & $2(9.52 \%)$ \\
\hline Poor weight gain & $2(9.52 \%)$ \\
\hline Decrease effort capacity & $17(80.95 \%)$ \\
\hline $\begin{array}{l}\text { Recent history of viral infection (respiratory, } \\
\text { gastrointestinal, both) }\end{array}$ & $20(95.23 \%)$ \\
\hline \multicolumn{2}{|l|}{ Laboratory } \\
\hline Fibrinogen (mg/dL) & $326 \pm 102.3$ \\
\hline CK (U/L) & $162.8 \pm 156.9$ \\
\hline CK-MB (U/L) & $66.65 \pm 39.30$ \\
\hline ASAT (U/L) & $34.45 \pm 18.00$ \\
\hline ALAT (U/L) & $26.80 \pm 14.71$ \\
\hline LDH (U/L) & $253.1 \pm 75.50$ \\
\hline Leukocytosis $(>10,000 / \mathrm{mm} 3)$ & $9(42.85 \%)$ \\
\hline Anemia (Hb <11 mg/dL) & $7(33.33 \%)$ \\
\hline Positive troponin I (qualitative assessment) & $7(33.33 \%)$ \\
\hline Positive CRP (qualitative assessment) & $11(52.38 \%)$ \\
\hline Elevated ESR & $9(42.85 \%)$ \\
\hline Positive serology for viral infection & $9(42.85 \%)$ \\
\hline \multicolumn{2}{|l|}{ ECG modifications } \\
\hline Sinus tachycardia & $4(19.04 \%)$ \\
\hline QRS axis deviation & $3(14.28 \%)$ \\
\hline Conduction disturbances (AV, BBB) & $4(19.04 \%)$ \\
\hline ST-T changes & $14(66.66 \%)$ \\
\hline \multicolumn{2}{|l|}{ 24h Holter ECG modifications } \\
\hline Sinus tachycardia & $1(4.76 \%)$ \\
\hline Ventricular extra systolic dysrhythmia & $4(19.04 \%)$ \\
\hline No rhythm or conduction abnormalities & $16(76.19 \%)$ \\
\hline \multicolumn{2}{|l|}{ 2D transthoracic echocardiography } \\
\hline $\begin{array}{l}\text { Preserved systolic and diastolic function, no } \\
\text { structural changes* }\end{array}$ & $11(52.38 \%)$ \\
\hline $\begin{array}{l}\text { Preserved systolic and diastolic function, } \\
\text { with structural changes* }\end{array}$ & $3(14.28 \%)$ \\
\hline LVEF $\leq 30 \%$ & $7(33.33 \%)$ \\
\hline $\mathrm{dP} / \mathrm{dt} \leq 800 \mathrm{mmHg}$ & $5(23.80 \%)$ \\
\hline Significant mitral regurgitation & $7(33.33 \%)$ \\
\hline \multicolumn{2}{|l|}{ Cardiac magnetic resonance $(n=10)$} \\
\hline No modifications & $2(9.52 \%)$ \\
\hline Diagnostic CMR criteria for myocarditis** & $8(38.09 \%)$ \\
\hline \multicolumn{2}{|l|}{ Diagnostic endomyocardial biopsy } \\
\hline Not performed & $18(85.71 \%)$ \\
\hline Performed & $3(14.28 \%)$ \\
\hline
\end{tabular}

formed to identify predictive factors associated with inhospital mortality in pediatric patients with acute myocarditis. All the performed tests were two-tailed, and the statistical significance of the study was set at an alpha coefficient of 0.05 .

\section{RESULTS}

The baseline clinical, laboratory, ECG, and imaging characteristics of the 21 study patients are presented in Table 1. The mean age of the study population was $99.62 \pm$ 77.25 months (ranging from 1 month to 204 months), and $61.90 \%(n=13)$ of the patients were males. The in-hospital mortality rate was $23.9 \%(n=5$, out of which $40 \%$ males; $n=2$ ). From the total number of deceased patients, 2 were infants (average age 3.83 months). The analysis of clinical presentation and medical history revealed that the most common symptom at presentation was decreased effort capacity $(80.95 \%, \mathrm{n}=17)$ followed by respiratory symptoms such as dyspnea and tachypnea (52.38\%, $\mathrm{n}=11)$, and that $95.23 \%(\mathrm{n}=20)$ of patients presented a recent history of viral infection. Sixteen patients $(80 \%)$ had a respiratory tract infection, $3(14.28 \%)$ presented a viral infection of the gastrointestinal tract, and 1 patient (4.76\%) had both respiratory and gastrointestinal symptoms (Figure 1). However, only $66.66 \%$ of the patients (n $=14$ ) had confirmed serology for a certain viral infection. Regarding the ECG changes, most patients presented STsegment and $\mathrm{T}$-wave changes $(66.66 \%, \mathrm{n}=14)$, while the 24h ECG recording identified ventricular extrasystolic dysrhythmia $(19.04 \%, \mathrm{n}=4)$, and no significant changes in the majority of patients $(76.19 \%, \mathrm{n}=16)$.

All patients underwent 2D transthoracic echocardiography examination, which identified a preserved systolic and diastolic left ventricular function with no structural

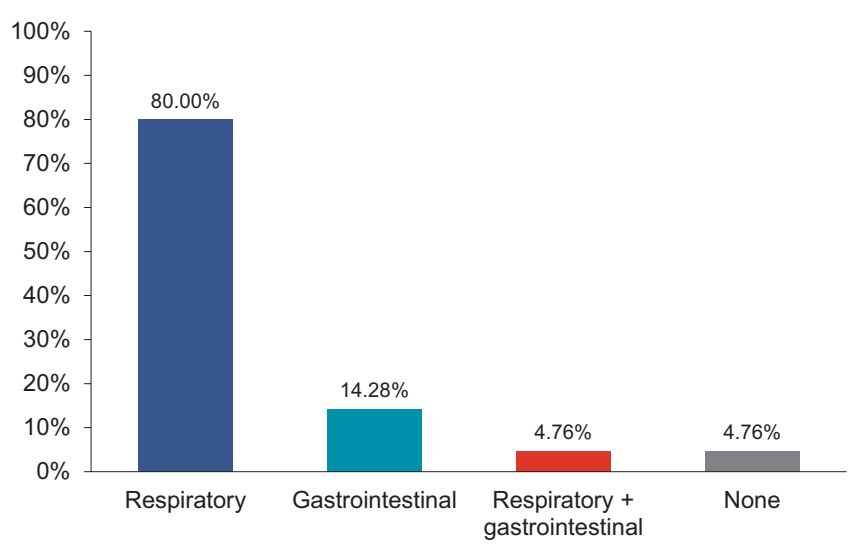

FIGURE 1. Type of recent history of viral infection among the total study population 
A



B

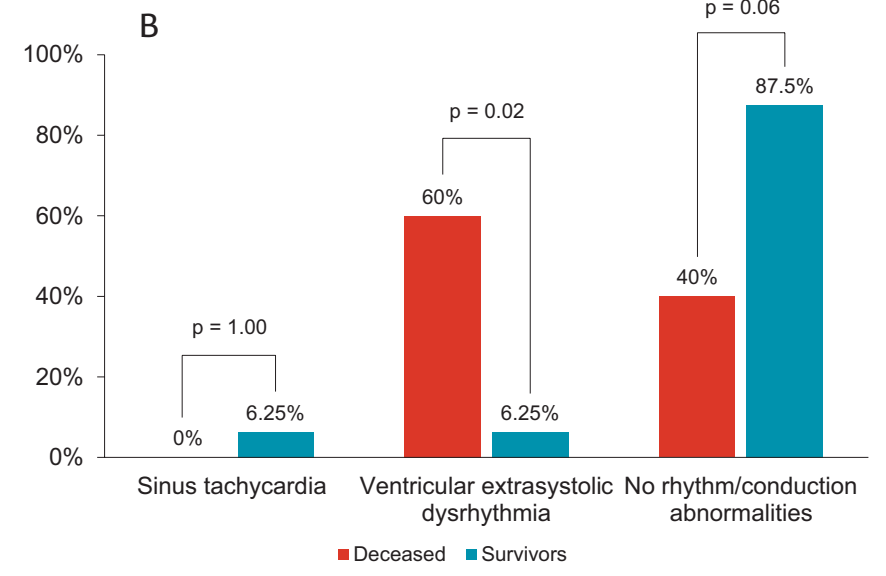

FIGURE 2. A - ECG changes on the 12-lead surface ECG in the two groups; B - ECG changes recorded on the $24 \mathrm{~h}$ Holter recording in the two groups

changes in $52.38 \%$ of cases $(n=11)$ and a severely impaired left ventricular ejection fraction of less than $30 \%$ (mean LVEF $20.71 \pm 6.5 \%)$ in $33.33 \%$ of the cases $(n=7)$.

Imagistic investigations were completed by a cardiac MRI in 10 patients, demonstrating positive criteria for acute myocarditis in 8 of them (38.9\%).

Comorbidities were present in $52.4 \%$ of the cases ( $\mathrm{n}=11$ ), including recurrent bronchiolitis in 2 children (9.5\%), or immunoglobulin A deficit in 2 children (9.5\%). Also, one child was obese, one child had chronic adenoiditis, and one child had allergic rhinitis.

Patients in the deceased group were significantly younger than the survivors $(55.60 \pm 56.18$ months vs. $113.4 \pm 78.50$ months, $\mathrm{p}=0.039$ ). There was no statistically significant difference between the deceased and survivors regarding gender $(\mathrm{p}=0.325)$, the presence of digestive $(p=1.000)$ or respiratory symptoms $(p=0.310)$, sensory

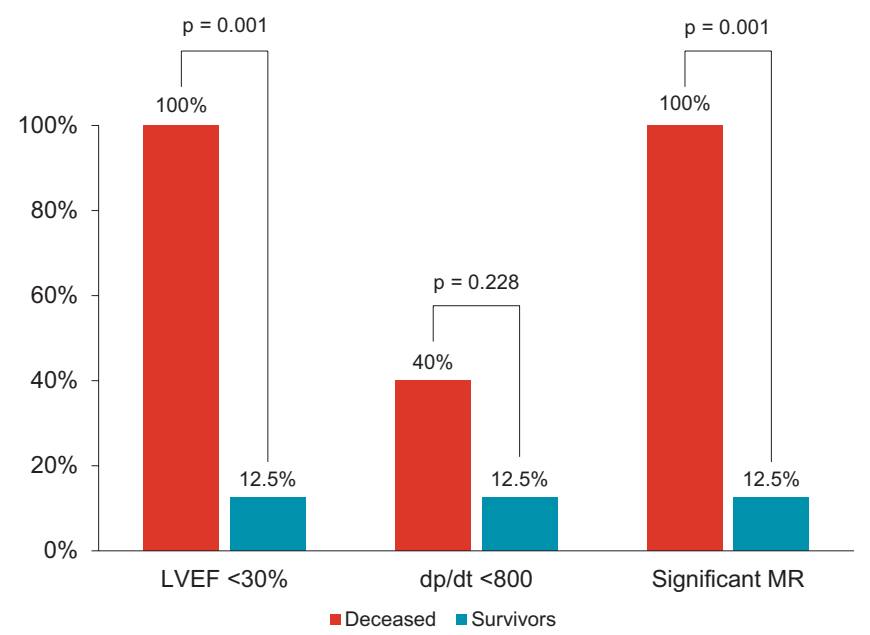

FIGURE 3. Echocardiographic predictors for in-hospital mortality in patients with acute myocarditis deficit ( $\mathrm{p}=0.428)$, poor weight gain $(\mathrm{p}=0.428)$, or decreased effort capacity $(\mathrm{p}=1.000)$. However, patients in the deceased group presented a significantly higher rate of hepatomegaly compared to survivors (100\% vs. $18.75 \%$, $\mathrm{p}=0.002$ ), while chest pain as an initial presentation symptom was more frequently present in the survivor group ( $0 \%$ vs. $62.5 \%, \mathrm{p}=0.03$ ).

Laboratory tests revealed no significant differences between the two groups regarding the complete blood count, troponin levels $(\mathrm{p}=0.123)$, erythrocyte sedimentation rate ( $p=0.338$ ), positive $\mathrm{C}$-reactive protein (qualitative assessment) $(p=0.635)$, or liver enzymes (ASAT: $p=0.887$; ALAT: $p=0.450$ ). However, patients that had deceased presented a significantly higher level of LDH $(365 \pm 21.38 \mathrm{U} / \mathrm{L}$ vs. $234.4 \pm 63.30 \mathrm{U} / \mathrm{L}, \mathrm{p}=0.0002$ ).

There were no statistically significant differences between the deceased and survivors regarding electrocardiographic changes on the surface ECG; however, the $24 \mathrm{~h}$ Holter monitoring showed that there was a significantly higher rate of ventricular extrasystolic dysrhythmias in patients that had deceased compared to survivors (Figure 2).

The transthoracic 2D echocardiography showed that patients who had deceased presented more frequently an impaired left ventricular ejection fraction $(<30 \%)$ ( $p=0.001$ ) and a significantly higher rate of severe mitral regurgitation ( $\mathrm{p}=0.001$ ) compared to survivors (Figure 3 ).

The viral infection confirmed via serology did not influence the study end-point in the analyzed population, with the exception of a Mycoplasma pneumoniae infection, which was present in 2 cases $(9.52 \%)$, both in the deceased group (Table 2).

Multivariate analysis identified that the most powerful predictors for in-hospital mortality in pediatric patients admitted for acute myocarditis were the presence of ven- 
TABLE 2. Distribution of confirmed viral infection in the study groups

\begin{tabular}{lcccccc}
\hline & $\begin{array}{c}\text { Total } \\
\mathbf{n = 2 1}\end{array}$ & $\begin{array}{c}\text { Deceased } \\
\mathbf{n = 5}\end{array}$ & $\begin{array}{c}\text { Survivors } \\
\mathbf{n = 1 6}\end{array}$ & $\mathbf{p}$ & OR & $\mathbf{9 5 \%}$ CI for OR \\
\hline Coxsackie virus & $5(23.80 \%)$ & $1(20 \%)$ & $4(25 \%)$ & 1.0000 & 0.7500 & $0.063-8.839$ \\
Echovirus & $1(4.76 \%)$ & $1(20 \%)$ & $0(0 \%)$ & 0.2381 & 11.00 & $0.379-318.9$ \\
Epstein-Barr virus & $3(14.28 \%)$ & $2(40 \%)$ & $1(6.25 \%)$ & 0.1278 & 10.00 & $0.670-149.1$ \\
Cytomegalovirus & $1(4.76 \%)$ & $0(0 \%)$ & $1(6.25 \%)$ & 1.0000 & 0.9394 & $0.033-26.67$ \\
Mycoplasma pneumoniae & $2(9.52 \%)$ & $2(40 \%)$ & 0 & 0.0476 & 23.57 & $0.915-607.2$ \\
Parvovirus & $1(4.76 \%)$ & $0(0 \%)$ & $1(6.25 \%)$ & 1.0000 & 0.9394 & $0.033-26.67$ \\
Enterovirus & $1(4.76 \%)$ & $0(0 \%)$ & $1(6.25 \%)$ & 1.0000 & 0.9394 & $0.033-26.67$ \\
Negative serology & $8(38.09 \%)$ & $1(20 \%)$ & $7(43.75 \%)$ & 0.6065 & 0.3214 & $0.029-3.558$ \\
Not determined & $4(19.04 \%)$ & $1(20 \%)$ & $3(18.75 \%)$ & 1.0000 & 1.083 & $0.086-13.55$ \\
\hline
\end{tabular}

tricular extrasystolic dysrhythmias on the $24 \mathrm{~h}$ Holter ECG monitoring, impaired left ventricular systolic function ( $\mathrm{LVEF}<30 \%$ ), the presence of severe mitral regurgitation, and confirmed infection with Mycoplasma pneumoniae (Table 3).

\section{DISCUSSIONS}

In this retrospective study, we aimed to identify factors associated with in-hospital mortality in pediatric patients admitted with acute myocarditis. We analyzed the clinical presentation, the laboratory (CBC, biochemical analysis) and serology testing, as well as the electrocardiography changes and the imaging data acquired via transthoracic echocardiography and CMR.

A clear-cut definition of the clinical diagnosis of acute myocarditis remained elusive. Clinical manifestations are extremely varied, from an asymptomatic disease to clinical signs of heart failure. In children with myocarditis, a history of viral infection can be frequently identified.
The diagnosis of myocarditis is usually based on complex clinical and paraclinical data. Endomyocardial biopsy is the gold standard diagnosis technique for inflammatory heart disease, but when histological sampling is performed in a limited area, it can lead to false negative results, while CMR enables the identification of myocarditis in all cases. ${ }^{13,22-25}$ In our study population, the clinical presentation varied from the presence of peripheral edema and hepatomegaly as signs of congestive heart failure, to respiratory and digestive symptoms which may also be signs of viral infections that have led to the occurrence of acute myocarditis. Other clinical signs and symptoms included sweating, chest pain, sensory deficit, poor weight, gain and decreased effort capacity. Interestingly, the presence of hepatomegaly was associated with higher mortality rates, whilst chest pain was more frequent among those who had survived during hospitalization. The higher rate of chest pain as a presentation symptom in the survival group could indicate the presence of myopericarditis, which has been described as a

TABLE 3. Multivariate analysis for predictors of in-hospital mortality in pediatric patients hospitalized for acute myocarditis

\begin{tabular}{lccc}
\hline Parameter & $\mathbf{p}$ & $\mathbf{O R}$ & $\mathbf{9 5 \%}$ CI for OR \\
\hline Gender, male & 0.325 & 0.30 & $0.03-2.42$ \\
Recent history of viral infection & 1.0000 & 1.06 & $0.03-30.22$ \\
Positive serology for viral infection & 0.6108 & 2.50 & $0.31-19.54$ \\
ST-T changes & 0.5975 & 0.50 & $0.06-4.15$ \\
Ventricular extra systolic dysrhythmia & 0.0276 & 22.50 & $1.50-335.6$ \\
LVEF $\leq 30 \%$ & 0.0010 & 63.80 & $2.62-155$ \\
dP/dt $\leq 800$ mmHg & 0.2281 & 4.66 & $0.45-47.66$ \\
Significant mitral regurgitation & 0.0010 & 63.80 & $2.62-155$ \\
Mycoplasma pneumoniae infection & 0.0476 & 23.57 & $0.91-607.2$ \\
\hline
\end{tabular}


primary pericarditis syndrome, with minor myocardial involvement. ${ }^{26}$

Despite being the gold-standard diagnostic method, EMB was only performed in 3 cases (14.28\%). Generally, EMB is considered safe in adult populations with suspected myocarditis. However, it is rarely performed in the pediatric age group, both due to the lack of available facilities and experience, as well as because of the associated risk for myocardial injury and intraprocedural complications. ${ }^{27,28}$

The etiology of myocarditis can be infectious, autoimmune, and toxic, with a predominance of a viral origin. Typically, the etiological culprit for viral myocarditis has included Adenovirus, Epstein-Barr virus, Coxsackie types A and B, Echovirus, Parvovirus B19, and Cytomegalovirus. This can be explained by the fact that they have a common receptor at the myocyte level. ${ }^{29,30}$ In our study population, the most common viral etiology included Coxsackie and Epstein-Barr virus. Two patients presented Mycoplasma pneumoniae infection, which was significantly associated with in-hospital mortality. Mycoplasma pneumoniae is a pathogen that generally causes respiratory tract infections, but it may present with cardiac involvement via several proposed pathogenic mechanisms including direct invasion of the myocardium through the lymphatic or circulatory systems, or through autoimmune response. Myocardial involvement is generally present in adults, but it should be tested in the pediatric population in case of suspicion, thus ensuring the initiation of appropriate treatment which decreases the rate of life-threatening complications. ${ }^{31,32}$

Lee et al. identified older age, low initial ejection fraction, occurrence of a nonfatal cardiac arrest, and ventricular arrhythmia as significant risk factors for a fatal outcome. ${ }^{33}$ In our study, patients that had deceased were significantly younger, with a higher rate of ventricular rhythm disturbance identified on the 24h Holter ECG monitoring, with a more impaired left ventricular systolic function and the presence of severe mitral regurgitation. Infants are more severely affected by the acute inflammation of the myocardium, thus are more likely to present with cardiogenic shock, acute heart failure, or the need for advanced circulatory and respiratory support, earlier from disease onset, compared to older children. ${ }^{34}$ The 12 lead surface ECG is a mandatory examination in patients with confirmed or suspected myocarditis, but it may not reveal significant changes initially. However, in pediatric patients, several retrospective studies have reported abnormal ECG tracings in up to $93-100 \%$ of myocarditis cases. ${ }^{35-37}$ A retrospective study on 85 patients with ful- minant myocarditis aimed to study the in-hospital development of arrhythmias and found that $45 \%(n=38)$ of patients presented with acute (during presentation) or subacute (over the course of hospitalization) rhythm disturbances. Moreover, the presence of arrhythmias was associated with worse outcomes (mechanical circulatory support, heart transplant, or death; OR 7.59, 95\% CI: 2.61-22.07).$^{38}$ Another study showed that the presence of ventricular tachy- and bradyarrhythmias was associated with the need for extracorporeal membrane oxygenation therapy, as well as with a higher mortality. ${ }^{39}$ Therefore, the identification of acute and subacute ventricular dysrhythmias may aid in the selection of patients at higher risk of acute complications and death, thus ensuring the application of intensive care measures.

Echocardiography remains the most useful diagnostic test in cases with clinical suspicion of myocarditis. Routine echocardiographic diagnostic criteria include left ventricle dilation (Dubois formula), ejection fraction $<30 \%$, significant mitral regurgitation, as well as the $\mathrm{dp} /$ dt parameter with a value below 800 mmHg. ${ }^{19-22,40}$ Despite being the most useful imaging technique for identifying structural and functional changes, there are no specific echocardiographic criteria for the diagnosis of myocarditis, and these changes are generally not enough to differentiate from other forms of cardiomyopathies. In agreement with previous studies, we also found that a decreased left ventricular ejection fraction is associated with worse in-hospital outcomes, which again established the role of bedside echocardiography in providing diagnostic, therapeutic, and prognostic information in this subset of patients. $^{24}$

MRI is a promising diagnostic method for myocarditis. Imaging investigations were completed by a cardiac MRI with contrast in 10 cases, which described a positive criterion (Lake Louise) for myocarditis in 8 cases. ${ }^{19-21,25,41}$

The present study has depicted a series of clinical and paraclinical factors that can predict worse in-hospital outcomes of pediatric patients that are admitted for acute myocarditis. The presence of ventricular dysrhythmia on the $24 \mathrm{~h}$ Holter monitoring, the impaired left ventricular ejection fraction, and the confirmed infection with $\mathrm{Myco-}$ plasma pneumoniae were found to be the most significantly associated with the occurrence of in-hospital death. The main limitations of the present study are its retrospective nature and the relatively low number of patients. Future prospective studies on the matter are required in order to define a more precise predictive tool for both short- and long-term outcomes of patients with acute myocarditis within the pediatric age group. 


\section{CONCLUSIONS}

Acute myocarditis remains a diagnostic challenge for the pediatric practitioner. An accurate integrated clinical approach is necessary in case of suspected myocarditis. The most powerful predictors for in-hospital mortality in pediatric patients admitted for acute myocarditis were the presence of ventricular extrasystolic dysrhythmias on the 24h Holter ECG monitoring, impaired left ventricular systolic function (LVEF $<30 \%$ ), the presence of severe mitral regurgitation, and confirmed infection with Mycoplasma pneumoniae. Further prospective studies on larger patient cohorts are required in order create a prediction tool for in-hospital mortality, as well as for the long-term outcomes of pediatric patients admitted for acute myocarditis.

\section{CONFLICT OF INTEREST}

Nothing to declare.

\section{REFERENCES}

1. Kindermann I, Kindermann M, Kandolf R, et al. Predictors of Outcome in patients with suspected Myocarditis. Circulation. 2008;118:639-648. doi: 10.1161/circulationaha.108.769489.

2. Levine $M C$, Klugman $D$, Teach SJ. Update on myocarditis in children. Curr Opin Pediatr. 2010;22:278-283. doi: 10.1097/ MOP.ob013e32833924d2.

3. Kindermann I, Barth C, Mahfoud F, et al. Update on myocarditis. J Am Coll Cardiol. 2012;59:779-792. doi: 10.1016/j. jacc.2011.09.074.

4. Dennert R, Crijns HJ, Heymans S. Acute viral myocarditis. Eur Heart J. 2008;29:2073-2082. doi: 10.1093/eurheartj/ehn296.

5. Allan CK, Fulton DR. Clinical manifestations and diagnosis of myocarditis in children. Available at: https://www.uptodate. com/contents/clinical-manifestations-and-diagnosis-ofmyocarditis-in-children.

6. Yajima T, Knowlton KU. Viral Myocarditis: From the Perspective of the Virus. Circulation. 2009;119:2615-2624. doi: 10.1161/CIRCULATIONAHA.108.766022.

7. Uhl TL. Viral Myocarditis in Children. Crit Care Nurse. 2008;28:42-63.

8. Vashist S, Singh GK. Acute Myocarditis in Children Current Concepts and Management. Curr Treat Options Cardiovasc Med. 2009;11:383-391.

9. Caforio AL, Pankuweit S, Arbustini E, et al. Current state of knowledge on aetiology, diagnosis, management, and therapy of myocarditis: a position statement of the European Society of Cardiology Working Group on Myocardial and Pericardial Diseases. Eur Heart J. 2013;34:2636-2648. doi: 10.1093/ eurheartj/eht210.

10. Canter CE, Simpson KE. Diagnosis and Treatment of Myocarditis in Children in the Current Era. Circulation. 2014;129:115-128. doi: 10.1161/CIRCULATIONAHA.113.001372.

11. Caforio AL, Mahon NJ, McKenna WJ. Cardiac autoantibodies to myosin and other heart-specific autoantigens in myocarditis and dilated cardiomyopathy. Autoimmunity. 2001;34:199204. doi: 10.3109/08916930109007385.

12. Caforio AL, Vinci A, Iliceto S. Anti-heart autoantibodies in familial dilated cardiomyopathy. Autoimmunity. 2008;41:462469. doi: 10.1080/08916930802031546.

13. Rodriguez-Gonzalez M, Sanchez-Codez MI, Lubian-Gutierrez M, Castellano-Martinez A. Clinical presentation and early predictors for poor outcomes in pediatric myocarditis: A retrospective study. World J Clin Cases. 2019;7:548-561. doi: 10.12998/wjcc.v7.i5.548.

14. Messroghli DR, Pickardt T, Fischer M, et al. Toward evidencebased diagnosis of myocarditis in children and adolescents: Rationale, design, and first baseline data of MYKKE, a multicenter registry and study platform. Am Heart J. 2017;187:133-144. doi: 10.1016/j.ahj.2017.02.027.

15. Caforio AL, Mahon NJ, Tona F, McKenna WJ. Circulating cardiac autoantibodies in dilated cardiomyopathy and myocarditis: pathogenetic and clinical significance. Eur J Heart Fail. 2002;4:411-417.

16. Schultheiss HP, Kühl U, Cooper LT. The management of myocarditis. Eur J Heart. 2011;32:2616-2625. doi: 10.1093/ eurheartj/ehr165.

17. Shauer A, Gotsman I, Keren A, et al. Acute Viral Myocarditis: Current Concepts in Diagnosis and Treatment. Isr Med Assoc J. 2013;15:180-185.

18. Bejiqi R, Retkoceri R, Maloku A, Mustafa A, Bejiqi H, Bejiqi R. The Diagnostic and Clinical Approach to Pediatric Myocarditis: A Review of the Current Literature. Open Access Maced J Med Sci. 2019;7:162-173. doi: 10.3889/oamjms.2019.010.

19. Friedrich GM, Sechtem U, Schulz-Menger J, et al. Cardiovascular Magnetic Resonance in Myocarditis: A JACC White Paper. J Am Coll Cardiol. 2009;53:1475-1487. doi: 10.1016/j.jacc.2009.02.007.

20. Chow LH, Radio SJ, Sears TD, McManus BM. Insensitivity of Right Ventricular Endomyocardial Biopsy in the Diagnosis of Myocarditis. J Am Coll Cardiol. 1989;14:915-920. doi: 10.1016/0735-1097(89)90465-8.

21. Cooper LT, Baughman KL, Feldman AM, et al. The Role of Endomyocardial Biopsy in the Management of Cardiovascular Disease. J Am Coll Cardiol. 2007;50:1914-1931. doi: 10.1016/j. jacc.2007.09.008.

22. Kuhn B, Shapiro ED, Walls TA, Friedman AH. Predictors of outcome of myocarditis. Pediatric Cardiology. 2004;25:374384. doi: 10.1007/s00246-003-0568-2.

23. Caforio ALP, Marcolongo R, Basso C. Clinical presentation and diagnosis of myocarditis. Heart. 2015:101. doi: 10.1136/ heartjnl-2014-306363.

24. Dominguez F, Kuhl U, Pieske B, Garcia-Pavia P, Tschope C. Update on Myocarditis and inflammatory cardiomyopathy: Reemergence of Endomyocardial Biopsy. Rev Esp Cardiol. 2016;69:178-187. doi: 10.1016/j.rec.2015.10.015.

25. AliBassiri H, Alizadehasl A, Sani ZA, et al. Transthoracic Echocardiography Versus Cardiac MRI in the Diagnosis of Acute Myocarditis. Arch Cardiovasc Imaging. 2015;3:e21211.

26. Imazio M, Cecchi E, Demichelis B, et al. Myopericarditis versus viral or idiopathic acute pericarditis. Heart. 2008;94:498-501. doi: 10.1136/hrt.2006.104067.

27. Sławek S, Araszkiewicz A, Gaczkowska A, et al. Endomyocardial biopsy via the femoral access - still safe and valuable diagnostic tool. BMC Cardiovasc Disord. 2016;16:222. doi: 10.1186/s12872-016-0406-0. 
28. Pophal SG, Sigfusson G, Booth KL, et al. Complications of endomyocardial biopsy in children. J Am Coll Cardiol. 1999;34:2105-2110. doi: 10.1016/s0735-1097(99)00452-0.

29. Fett JD. Diagnosis of viral cardiomyopathy by analysis of peripheral blood?. Expert Opin Ther Targets. 2008;12:10731075. doi: 10.1517/14728222.12.9.1073.

30. Kühl U, Pauschinger M, Seeberg B, et al. Viral persistence in the myocardium is associated with progressive cardiac dysfunction. Circulation. 2005;27. 112:1965-1970. doi: 10.1161/ CIRCULATIONAHA.105.548156.

31. Paz A, Potasman I. Mycoplasma-associated carditis. Case reports and review. Cardiology. 2002;97:83-88. doi: 10.1159/000057677.

32. Defilippi A, Silvestri M, Tacchella A, et al. Epidemiology and clinical features of Mycoplasma pneumoniae infection in children. Respir Med. 2008;102:1762-1768. doi: 10.1016/j. rmed.2008.06.022.

33. Lee KJ, McCrindle BW, Bohn DJ. Clinical outcomes of acute myocarditis in childhood. Heart. 1999;82:226-233. doi: 10.1136 hrt.82.2.226.

34. Amabile N, Fraisse A, Bouvenot J, Chetaille P, Ovaert C. Outcome of acute fulminant myocarditis in children. Heart. 2006;92:1269-1273. doi: 10.1136/hrt.2005.078402.

35. Durani Y, Giordano K, Goudie BW. Myocarditis and pericarditis in children. Pediatr Clin North Am. 2010;57:1281-1303. doi: 10.1016/j.pcl.2010.09.012.
36. Morgera T, Di Lenarda A, Dreas L, et al. Electrocardiography of myocarditis revisited: clinical and prognostic significance of electrocardiographic changes. Am Heart J. 1992;124:455467. doi: 10.1016/0002-8703(92)90613-z.

37. Freedman SB, Haladyn JK, Floh A, Kirsh JA, Taylor G, ThullFreedman J. Pediatric myocarditis: emergency department clinical findings and diagnostic evaluation. Pediatrics. 2007;120:1278-1285. doi: 10.1542/peds.2007-1073.

38. Miyake CY, Teele SA, Chen BAL, et al. In-Hospital Arrhythmia Development and Outcomes in Pediatric Patients with Acute Myocarditis. Am J Cardiol. 2014;113:535-540. doi: 10.1016/j. amjcard.2013.10.021.

39. Wu HP, Lin MJ, Yang WC, Wu KH, Chen CY. Predictors of Extracorporeal Membrane Oxygenation Support for Children with Acute Myocarditis. Biomed Res Int. 2017;2017:2510695. doi: 10.1155/2017/2510695.

40. Friedrich MG, Marcotte F. Cardiac Magnetic Resonance Assessment of Myocarditis. Circ Cardiovasc Imaging. 2013;6:833-839. doi: 10.1161/CIRCIMAGING.113.000416.

41. Kasner M, Sinning D, Escher F, et al. The utility of speckle tracking imaging in the diagnostic of acute myocarditis, as proven by endomyocardial biopsy. Int J Cardiol. 2013;168:30233024. doi: 10.1016/j.ijcard.2013.04.016. 